This item was submitted to Loughborough's Research Repository by the author.

Items in Figshare are protected by copyright, with all rights reserved, unless otherwise indicated.

\title{
What the minimum income standard tells us about living standards in the United Kingdom
}

PLEASE CITE THE PUBLISHED VERSION

https://doi.org/10.1108/978-1-78714-479-820171004

PUBLISHER

Emerald Publishing Ltd

VERSION

AM (Accepted Manuscript)

\section{PUBLISHER STATEMENT}

This work is made available according to the conditions of the Creative Commons Attribution-NonCommercialNoDerivatives 4.0 International (CC BY-NC-ND 4.0) licence. Full details of this licence are available at: https://creativecommons.org/licenses/by-nc-nd/4.0/

\section{LICENCE}

CC BY-NC-ND 4.0

\section{REPOSITORY RECORD}

Davis, Abigail, and Matt Padley. 2019. "What the Minimum Income Standard Tells Us About Living Standards in the United Kingdom". figshare. https://hdl.handle.net/2134/26667. 
WHAT THE MINIMUM INCOME STANDARD TELLS US ABOUT LIVING STANDARDS IN THE UK

Abigail Davis and Matt Padley

Centre for Research in Social Policy, Loughborough University

\section{Keywords}

Minimum Income Standards; living standards; income; adequacy; budget standards. 


\begin{abstract}
The Minimum Income Standard (MIS) research gives an insight into living standards in the UK, and provides a way of tracking the (in)adequacy of incomes over time. As such it offers useful context for discussions of inequality. At the core of the research are deliberative groups held with members of the public who identify and discuss the goods and services that are considered necessary for a living standard that provides a socially acceptable minimum. Groups decide not only what is enough to maintain health and well-being, but also what is needed for social inclusion. This chapter begins with an outline of the Minimum Income Standard (MIS) before exploring what the qualitative data from the research tell us about how people conceptualise socially acceptable living standards. These data also reveal how particular items, opportunities and choices are considered important in enabling individuals to feel socially included and how that has changed over time. The chapter then moves to look at how this living standard relates to UK household incomes, looking at the adequacy of income relative to MIS, in the years following the great recession. We identify the groups that face the greatest risk of having inadequate incomes and explore how the risk of having insufficient income has changed during a period in which there has been a sustained decline in living standards. In combining qualitative and quantitative findings from a decade of research, this chapter provides rich insight into living standards and their relation to income within the UK.
\end{abstract}


What the Minimum Income Standard tells us about living standards in the UK

\section{Introduction}

The Minimum Income Standard (MIS) represents the income that people need in order to have a minimum socially acceptable standard of living in contemporary UK society, rooted in public consensus. MIS provides a rich description of what a publically determined, decent living standard is, translated into weekly budgets, and consequently incomes, needed by different households in order to reach this standard. Thus it both describes a minimum living standard, negotiated and agreed by members of the public, and establishes a regularly updated threshold against which the adequacy of household incomes over time can be assessed and tracked.

MIS provides a window on public conceptions of adequacy and what a decent standard of living is in a way that other living standards indicators such as relative income thresholds are not able to. As a consequence, the weekly budgets and income requirements that are a product of MIS are based on shared understandings of what the public think everyone should be able to have in order to reach this minimum living standard in contemporary society, rather than simply being income thresholds drawn at an arbitrary level, unrelated to and divorced from any sense of what living standard such an income would provide.

The topic of living standards is one that has grown in prominence since the great recession which began in 2008. In the 2010 UK general election both Conservative and Labour manifestos included commitments to improving living standards: Labour (2010) set out plans for 'prosperity for all, not just a few', aiming to 'put more wealth in the hands of British people', while the Conservatives (2010) aimed to tackle rising inequality and poverty, ensuring the 'whole country shares in prosperity'. In the five years between the 2010 and 2015 general elections, living standards remained central to much public and political debate. Real terms falls in wages and stagnant incomes in the post-2008 period were seen to be contributing to the most significant decline in, and challenge to, living standards in living memory (Cribb, Hood, Joyce, \& Phillips, 2013). The cost of living crisis (e.g. Haddad, 2012; The Labour Party, 2015) was seen variously as a product of cuts to benefits, falling incomes, changes in the nature of employment, and the increasing cost of essentials (Davis, Hirsch, \& Padley, 2014; Hirsch, 2013a). There was - and is - a broad agreement that 'the best measures of living standards have fallen sharply and to an unprecedented degree since 2009' meaning that it had 'become harder to live a comfortable life on a modest or even typical income in modern Britain’ (Plunkett, Hurrell, \& Whittaker, 2014). 
In the context of such significant challenges to living standards arising as a consequence of the great recession, tracking what has happened to living standards since 2008 becomes a critical undertaking. Over the past twenty years, assessments of living standards and levels of poverty and inequality in the UK have largely been charted through the government produced Households Below Average Income (HBAI) data series (see Department for Work and Pensions, 2017). This series has included the government's preferred indicator of poverty, with a threshold set at $60 \%$ of median equivalised household income, and has set out how the risk of having an income below this level varies according to household composition and characteristics, such as work status. In tracking the proportion of the population with incomes below $60 \%$ of the median, HBAI has provided the UK government with an annual update of the state of living standards, pegged to average incomes. However, because this way of tracking living standards is linked to incomes, periods of recession and falling incomes highlight the limitations of such relative income indicators. For example, the period since 2008 has been one during which real incomes have in general been below pre-recession levels. Median income fell sharply from a peak in $2009 / 10$, bottoming out in 2011/12 and 2012/13, and it is only since 2014/15 that incomes have risen above their level at the start of the recession (Figure 1): 
What the Minimum Income Standard tells us about living standards in the UK

Take in Figure (No.1) here

An important consequence of these changes in incomes since 2008/09 is that the median income benchmark, to which the Governments' preferred indicator of poverty is pegged, has fallen at points in this period. This means that some households will have risen above the $60 \%$ median threshold, not because of any change in their incomes or material circumstances, but because of the downward movement of the threshold. In other words, it is not an increase in living standards that sees fewer households counted as living in poverty, but rather this trend is a product of falling incomes lowering an arbitrary threshold.

In these circumstances, MIS offers a different and invaluable way both of tracking changes in and conceiving of living standards in the period since 2008. MIS provides a 'definition' of a minimum living standard, constructed by the public, which in turn provides the basis for 'measuring' (Walker, 1987) who is above and below this defined living standard. This link between the definition and measurement of living standards is often missing from more arbitrarily defined thresholds, such as relative income indicators. The remainder of this chapter looks in greater detail at what the Minimum Income Standard approach, and programme of research and analysis, tell us about contemporary living standards. We begin by providing an overview of the MIS approach, including both a review of its origins and underpinnings, and an account of the MIS method. The chapter then sets out the qualitative insights revealed through MIS about living standards in the UK over the past decade, how minimum living standards are defined and what, if anything, has changed over this period. Having explored the 'definitional task' central to MIS, we turn to look at 'measurement': what the Minimum Income Standard tells us about what has been happening in terms of the adequacy of incomes relative to MIS since 2008 and how this relates to other 'measures'.

\section{The Minimum Income Standard}

The Minimum Income Standard approach stems from a move away from the concept of 'absolute need', towards one in which poverty means not being able to have what is 'customary', 'or at least widely encouraged or approved' in a given society (Townsend, 1979: 31). In 1987, Walker suggested that the 'participatory social minimum' that Townsend sought to define would be best operationalised by building consensus among members of the public about what it means to be able to participate in society. Based on these ideas, MIS 
research identifies a context-specific threshold of need, rooted in contemporary ideas and experiences of living standards, and is defined and described through decisions made by members of the society in which it is situated.

Unlike other research, which attempts to measure and define poverty by asking what people lack (e.g., Gordon, et al. 2013; Smith, et al. 2015), MIS therefore seeks to answer the question 'what is enough?' and focuses on defining adequacy. Rather than examining what is lacked by those on low incomes, it seeks public consensus across socio-economic groups about what is needed by any citizen in order to have a minimum socially acceptable standard of living. In this respect there are similarities with 'consensual' approaches, such as those used in deprivation surveys, and that of Mack and Lansley (1985). However, MIS differs from these studies in two key methodological aspects. Firstly, in MIS, participants have free rein to discuss whichever items they consider to be worthy of discussion. In contrast, other work relies on the use of quantitative surveys, presenting respondents with a pre-defined list from which they identify what they think is essential. Secondly, in surveys not only are the items participants are asked to consider limited to a specific predetermined list, but so are the possible responses. MIS is based on Walker's (1987, p. 221) premise that 'to be true to the consensual approach, people must be given scope to express their views. They need time to find their own words, to reflect on their own experience, and to grapple with the complexities of the subject.' The MIS approach involves a series of deliberative groups usually involving 8-10 people, who are brought together to discuss and decide on what someone like them needs to have this living standard. Participants are able to bring their experience to bear in working together to reach an understanding of whether or not something is needed, and explore the reasons why that is the case.

The groups are demographically similar, meaning that pensioners discuss the needs of pensioners, parents discuss the needs of parents and children, and working age adults without children discuss what is needed by this group. However, the participants are drawn from a range of socio-economic backgrounds so that people with different perspectives and experiences from across society can contribute to the negotiated consensus.

Central to the MIS approach in the UK is a definition of this living standard, which encapsulates Townsend's idea that an acceptable minimum should not purely be about survival or subsistence, but should incorporate social inclusion: "A minimum standard of living in the UK today includes, but is more than, just food, clothes and shelter. It is about having what you need in order to have the opportunities and choices necessary to participate in society” (Davis, et al. 2014). 
What the Minimum Income Standard tells us about living standards in the UK

This definition, which was developed through thematic analysis of group discussions held at the beginning of the original MIS research in 2006, has been used throughout all the subsequent group discussions. In presenting it to participants, group moderators emphasise that the standard envisaged is above survival, but is also one that centres on needs rather than wants. Participants are asked to work together to identify firstly what the needs of a hypothetical individual like themselves (or a 'case study') would be, and then how they would meet those needs as a minimum, based on their experiences and knowledge of what it is like to be an individual and/or part of a household in today's society. The focus on a case study, rather than a more general discussion of individual needs is important to encourage a collective objectivity, rather than individual subjectivity, within the group - so they are responsible for defining and describing the needs of someone like themselves, but not discussing or imposing their own personal needs and preferences on the decision-making process.

The groups are held in iterative stages, involving new participants at each stage in order to broaden consensus. The first stage of groups construct lists of goods and services that would be needed by the case study individual under discussion. Subsequent phases give new groups the opportunity to review and revise these lists, highlight and remedy omissions or over-provision and resolve any outstanding issues. The lists compiled for the different individuals (single and partnered pensioners, single and partnered working age adults and single and partnered parents, infants, toddlers, preschool, primary and secondary school aged children) are priced at the retailers identified by groups, with each item given a lifetime or replacement rate which can then be divided into a weekly cost. From this, weekly budgets are calculated. Individual budgets can be combined to reflect different household compositions, taking into account, where relevant, any economies of scale or particular needs for larger households, such as a larger family car for households with three or more children. Thus, it is these qualitative discussions and the negotiated decisions that underpin the final calculations of weekly budgets and earnings requirements (taking into account tax and benefit rules).

\section{MIS as a rich description of living standards}

The first MIS report was published in 2008 and followed a period of relative prosperity in the UK, which then gave way to the 'great recession', austerity measures and in recent years a partial recovery, although living standards in real terms have not significantly 
improved owing to stagnation in earnings and rising living costs, as noted above. During this period, new MIS research has been conducted every two years, and this has given us a wealth of data in which participants discuss and explain what is needed (or not needed) and why, item by item. There are various types of rationale brought to bear in discussions about what is needed (see Davis, Hirsch, Padley, \& Marshall, 2015). Sometimes the reasons why an item is required may be self-evident: for instance, people need a toothbrush in order to maintain personal hygiene and dental health. In other cases, the emphasis is on what is needed in order for someone to feel socially included - following Townsend's idea of a 'participatory social minimum'. This can manifest itself in different ways: from being able to have a hospitable home one can welcome guests into without shame, being appropriately dressed for work or a special occasion, being able to socialise with friends, or providing children with a gift to take to a birthday party. What has emerged is that each round of research provides a snapshot of what a minimum acceptable standard of living comprises for the individuals and families living in the UK at that point.

\section{Changes over time}

Much of the contents of the lists compiled by groups, in particular household goods, furniture, food and drink for consumption at home, clothing and the many items relating to health and personal care have stayed remarkably stable. This demonstrates that in many respects people's day-to-day lives, and expectations about what constitutes a minimum standard of living, have stayed very similar over time: people eat the same food, wear the same kinds of clothes and keep the same things in their bathroom cabinets and kitchen cupboards. However, there are some notable exceptions, which offer valuable insights into changes in societal norms and expectations regarding living standards.

A prominent example of change over time relates to how people talk about technology in terms both of what is needed and why. With regards to technology, there are items that have remained relatively unchanged over time. For example, a television has been included for all of the different households covered by MIS since 2008, principally because groups of members of the public agree that it provides an inexpensive means of entertainment, as well as a source of news and current affairs for adults and of education for children. Groups agree that although some people might choose not to have a television, being unable to have one could result in people feeling isolated and unable to participate in conversations with friends and colleagues about what is going on in the world or about popular culture. While the inclusion of a television has been a constant feature of MIS, in 
2016 there were extensive discussions within groups about whether or not households would be able to meet their entertainment needs with a DVD player, as this was seen as technology that was rapidly becoming outdated. Groups reached consensus that as a DVD player is an inexpensive item and many people still own DVDs it should still be included as a minimum, and that current emerging alternatives (in particular subscription to streaming services such as Netflix) were above what was needed for a minimum standard of living, despite survey data showing that these are becoming more prevalent (Office for National Statistics, 2016). Continuing MIS research allows us to track how people live, and how they use and think about different items. In the case of the DVD player it will be interesting to see if it follows the same trajectory in falling ownership that the video cassette recorder (VCR) experienced.

Throughout the iterations of MIS, groups have agreed that a mobile phone is a requirement for all adults and secondary school age children, but the type of device and the way in which it is expected to be used has changed over time. Between 2008 and 2016 the description of the mobile phone included as part of a minimum budget moved from being a simple device meeting needs relating to safety - to be used only in emergencies when out of the house - to becoming something that provides and supports a range of different aspects of social participation, for example accessing information, listening to the radio, playing music and staying connected with work, friends and family via email, social networking and messaging.

At the start of MIS, in 2008, the public agreed that all households needed a landline phone and the mobile phone included was a basic, entry-level model meant chiefly for use in emergencies. In 2010, in the second round of MIS research, groups included a cheap monthly mobile contract, which included the costs of the handset and a limited amount of calls, texts and data for working age adults and secondary school age children. Working age adults in groups said that they would use mobile phones for routine calls, while secondary school children were more likely to be communicating with their friends by text. Contract deals were seen as providing a more cost effective option than pay-as-you-go calls and texts. Pensioners, however, maintained that a mobile phone was for use in emergencies, and so continued to include a pay-as-you-go phone with a modest amount for an occasional 'top up'. In 2012, participants said that telecommunication needs for most households would be met by a basic smartphone for each adult and secondary school age child, but that pensioners and parents still need a landline as a back-up because mobile phones can be lost, break or stop working. Groups discussing the needs of working age adults without children agreed that a landline was no longer necessary as part of a minimum socially acceptable standard of living 
for these households. They would instead access the internet via a dongle paid for by monthly subscription, with a modest amount added to a basic mobile phone package in order to allow for extra data each month.

Discussions about the need for access to computers and the internet have also reflected changes in society and societal norms. At the start of MIS in 2008, the only households where a home computer was identified as a minimum need were those including school age children, with secondary school age children also needing access to the internet at home in order to be able to do their homework. In subsequent iterations, parents of primary school age children noted that there was an increasing expectation from schools that pupils would be able to use the internet at home to research, complete and submit homework. Parents were in agreement that it was important for this to be included because children living at a minimum socially acceptable standard needed to have the same educational opportunities as their peers. Research looking at the 'digital divide' and digital exclusion, which has found that children and young people from lower socioeconomic groups are less likely to have access to the internet, and are less likely to take up opportunities available online (Livingstone \& Helsper, 2007; Chowdry, Greaves, \& Sibieta, 2010), points to the importance of the inclusion of internet access for households with children as part of a minimum standard of living.

In 2010 access to the internet within the home was identified as a need for all working age households, with and without children, and it was agreed that being restricted to accessing computers in public libraries would not be adequate within a minimum living standard (Hassani, 2006). Participants said that without this access people would be disadvantaged: the internet provides the ability to access information and employment opportunities, engage with financial services (e.g. through online banking) and government agencies (for example making tax credit and benefit claims), and to make the most of available household resources by being able to use price comparison websites and find discounts and deals only available online. Being unable to do so not only has implications for costs - linked to discussions of the cost of living in poverty and evidence that people on lower incomes are likely to pay higher prices for essentials, the 'poverty premium' (see Hirsch, 2013b) - but also means that people are excluded from goods, services and information that it is reasonable to expect everyone in society to be able to access (Foley, 2004; Hargittai \& Hinnant, 2008). Pensioners in 2014, for the first time, identified internet access in the home as a need and in 2016 a printer was added to the list of necessary items: in 
order to pursue interests and activities in retirement pensioners needed to be able to print, for example, important documents, recipes, email correspondence and so on.

The rapid development of technology, alongside the increasing proportion of many peoples' lives that are played out online, continues to have an impact on how minimum needs are met. For example, in 2016, working age adults debated at length whether the everexpanding capabilities of smartphones meant that households no longer needed an additional device for home computing, but concluded that there were still some activities (for example, filling in job applications or editing documents) that could not be completed on a mobile phone. Discussions such as this, which are central to MIS, reflect trends identified elsewhere: a survey conducted by Ofcom (2016) in the UK revealed, perhaps unsurprisingly, that people are increasingly reliant on smartphones, that these are the devices most used to access the internet, and that while pensioners are less likely to do so, their use of technology is growing.

Other notable changes emerging from MIS relate to transport. In 2008 all households agreed that they could meet their travel needs principally through public transport, with occasional taxi use. However, in 2012 parents said that households with children could no longer meet all of their needs in this way, and needed one second hand car per household. While previously car ownership might not have been considered necessary - and may even have been viewed as a luxury - public transport had ceased to be sufficiently affordable, accessible, or flexible. This view is supported by data showing that bus services have been reduced, altered and withdrawn over time, while at the same time fares have increased at a rate above inflation (Campaign for Better Transport, 2015). Without a car then, households with children would be unable to meet their transport needs, which would have a potentially negative impact on access to employment and social opportunities for both parents and children. Although working age adults' and pensioners' minimum transport needs are still based on use of public transport, the amount included for taxi fares has gradually increased over time, explained partly by rising prices and partly by reductions in local public transport services.

More subtle changes can be seen in how groups talk about meeting the need for social and cultural participation, particularly in the case of households with children. For example, when MIS research was first published, groups said that families should be able to eat out or have a takeaway meal once a month. This remained the case in 2010, but since 2012 parents eating out has become something that, while still seen as a need, is one that is more likely to be reserved for special occasions, for example to celebrate a family birthday, rather than a 
more routine part of social activities. Consequently the frequency of eating out as a family has been reduced from once a month to three or four times a year. This is an example of where parents are keen to maintain a certain standard of living and still think that is important that people can go out to eat 'to feel like everyone else', but consider the level at which this need can be met as a minimum.

Children's social participation, in terms of their development and socialisation when very young, and to socialise with their peers when older, have always been seen as an important part of the minimum living standard described by parents. In the initial research parents agreed that childminders would meet their childcare needs, and this remained the case through several iterations. However, in 2016 parents of young children, under school age, said that where families needed childcare, the minimum budgets should include provision for a place at nursery. Parents agreed that it was important, as a minimum, to be able to choose the best source of care for their child. Including the cost of childminding, rather than a nursery, risks excluding parents from accessing the best quality childcare available. There was consensus that the more formal setting offered by nurseries was better for preparing young children for the transition to full-time education. This change in emphasis is echoed in a change to government policy increasing the entitlement to free childcare hours from the current 15 to 30 hours each week for certain working families from September 2017, and by data showing a decrease in childminders and an increase in places taken up at day nurseries (Department for Education, 2017).

The budgets for primary school children have always included some money to pay for them to attend after school activities, such as cubs or brownies and parents have consistently agreed that it is important to be able to provide swimming lessons, as this is seen as a valuable life skill. In 2016 the amount allocated for these activities was increased by parents, who said that there were more activities being offered to children than there used to be, these were more likely to be available all year round (rather than only in term time) and that it was important that children were able to pursue interests and learn new skills in order to have the 'choices and opportunities to participate in society' in the MIS definition. This mirrors government strategies aimed to increase activity levels in children and young people, which include a commitment to ensure that all primary school aged children learn to swim (HM Government, 2015).

The examples set out here capture the kinds of debates and discussions that take place within the MIS groups tasked with reaching agreement about what a minimum socially acceptable living standard needs to include. As new MIS research has continued to be 
What the Minimum Income Standard tells us about living standards in the UK

undertaken every two years throughout the great recession and its aftermath, it is striking to see that although the numbers of individuals below or at risk of being below MIS have increased, the standard itself and the ways in which people describe it have stayed remarkably similar. However, where there are differences, MIS is able to capture and reflect these and give valuable insights into the way society and the choices people make are changing.

\section{Charting income adequacy and living standards}

In the preceding section, the focus was on what MIS reveals about the ways in which a minimum living standard is conceived of, defined and described by members of the public, and what this tells us about contemporary living standards in the UK and how expectations regarding these standards change over time. In definitional terms, MIS offers this rich description of what a publically determined, minimum socially acceptable standard of living is, but critically it also provides a means of tracking what has been happening to living standards as measured by the adequacy of household incomes relative to MIS. This section looks at the proportion of individuals who fall below the benchmark of income adequacy provided by MIS; those with incomes too low to be able to afford the things that the public have identified as necessary in order to meet their minimum material needs and participate in society. Looking at which individuals, in particular demographic groups, face the most significant risk of having inadequate income and at how this has changed over time makes a distinctive contribution to the ongoing debate and discussion around living standards and their trajectory. Comparing MIS to relative income indicators illustrates the importance of having benchmarks and indicators of living standards that do not fluctuate according to what is happening to median incomes.

The analysis presented here makes use of the latest available data from the annually updated Family Resources Survey (Department for Work and Pensions, National Centre for Social Research \& Office for National Statistics, 2016), comparing household income data from this survey with weekly minimum budget requirements established through the MIS research (see Padley, Hirsch, \& Valadez, 2017; Padley, Valadez, \& Hirsch, 2015; Padley \& Hirsch, 2013, 2014, 2016). On this basis, the risk of falling below MIS (based on post-tax income, after covering housing and childcare costs, both of which have a direct impact on levels of disposable income) can be estimated for around $80 \%$ of households in the UK for which MIS currently allows minimum budgets to be directly calculated. These are 
households comprising a single person or couple with or without dependent children, not households that include additional adults, such as non-dependent children. In order to provide an estimate of minimum income requirements for the whole population, a method for estimating the requirements of additional household members has been developed (Hirsch, Padley, \& Valadez, 2016): this means it is possible to produce MIS requirements for households with, for example, a mix of dependent and non-dependent children, multigenerational households or households comprising working-age adults 'sharers' (Hill, Hirsch, \& Padley, 2015; see also Padley et al., 2017).

Since the start of the great recession in 2008, many in the UK have encountered falling living standards. Figure 2 shows that over the six years between 2008/09 and 2014/15 the risk of having an inadequate income - that is, one below the level of MIS - has increased for all groups. The proportion of all individuals with incomes below MIS increased from a quarter of the population in 2008/09 (15.2 million) to just over 30\% (19.1 million) in 2014/15. This means that over this period nearly four million more individuals moved from having incomes that enabled them to meet all of their minimum needs to a situation where their household incomes were no longer sufficient to provide a publically defined and agreed minimum living standard. Although the relationship between low income and deprivation is a complex one (Berthoud \& Bryan, 2010; Whelan, Layte, Maitre, \& Nolan, 2001), where individuals and families do not have incomes sufficient to reach the MIS level, it is very likely that there is an increased risk of deprivation (Hirsch et al., 2016). Indeed, recent research with those living below the level of MIS (Hill, Davis, Hirsch, \& Marshall, 2016) shows that the pressures that come with living on a low income are not restricted to the estimated 668,000 households living on extremely low incomes or to those the most severe forms of poverty (Fitzpatrick et al., 2016). The increase in the number and proportion of individuals living below MIS, then, is an indication that, since the start of the recession, many more households will be faced with difficult decisions about prioritising certain areas of spending over others or about what to go without (Hill et al., 2016). That is, having an income below MIS means having to make adjustments to ways of living, foregoing possessions and activities that had become established social norms, heightening the risk of being excluded from ‘ordinary patterns, customs and activities' (Townsend, 1979).

Take in Figure (No.2) here 
What the Minimum Income Standard tells us about living standards in the UK

The risk of having an income below MIS has increased for all demographic groups, but this risk, and its consequent impact on living standards, is not distributed evenly across groups. Children face the greatest risk of being below MIS, while pensioners have largely been protected from the impact of the recession and have a far lower risk of having inadequate incomes. The proportion of children living in households with inadequate incomes, relative to MIS, increased from 39\% to 45\% between 2008/09 and 2014/15, meaning that around one million more children were living in families without sufficient income to provide all that the public agree is needed for a minimum socially acceptable standard of living at the end of this six year period compared to the start. Children currently comprise around one-fifth of the total UK population and yet with six million below MIS, account for nearly a third of all individuals below MIS. The uneven distribution of risk becomes even more apparent looking in more detail at how the risk of having insufficient income varies according to household composition. Children in lone parent families face a significant and increasing risk of being unable to reach MIS. While only around a quarter of all children live in lone parent families, $75 \%$ of these children do not have all that they need for a minimum standard of living; just over a third of children living in couple parent families (36\%) are below the level of MIS.

This evidence poses a real challenge to commitments from successive governments to eradicating child poverty by 2020 (e.g. HM Government 2010, 2014) and points to a continued - and difficult to halt - decline in the living standards of a growing number of children (cf. Brewer, Browne, \& Joyce, 2011). Perhaps more immediately concerning, the increasing number of children living below MIS are more likely to be growing up in families that cannot afford to pay for the activities taken for granted by other children and are less likely to have the things that other children have (Kyprianou, 2015; Hill et al., 2016; Pople, 2017; Ridge, 2002). For children growing up in lone parent families with incomes below and well below MIS, these inequalities are often felt particularly acutely, and forecasts suggest that the situation for lone parents is unlikely to improve in the near future: lone parent families have been particularly affected by changes to state support introduced through welfare reforms - such as the cuts in work allowances within Universal Credit - which have had the net effect of significantly reducing the value of state support (Hirsch, 2015; Rabindrakumar, 2013).

The decline in living standards that becomes apparent when looking at incomes relative to MIS since the start of the recession in 2008 is one that has been discussed elsewhere (Belfield, Cribb, Hood, \& Joyce, 2014; Plunkett et al., 2014) and the Institute for 
Fiscal Studies (Hood \& Waters, 2017), looking forward to 2021-22, predict enduring challenges for UK living standards: in particular, continued increases in income inequality and in the government-preferred relative income indicators of overall and child poverty. However, looking back over the period since 2008 this government-preferred 'measure' has failed to pick up on the decline in living standards principally because of falls in the median income benchmark to which relative poverty indicators are tied - as incomes have fallen so too has the 'poverty line'. A comparison of incomes relative to the MIS threshold and the relative poverty indicator reveals a clear contrast. Figure 3 shows the changes in the proportion of the population falling below the MIS and relative income thresholds. While the relative poverty indicator shows a reduction in poverty levels over this period, the MIS indicator shows the opposite, namely that the period since the great recession has been one in which living standards have declined not improved.

Take in Figure (No.3) here

The 'below MIS' indicator signals a reduction in the adequacy of incomes over time or an increase in the proportion of individuals lacking all that is needed for a minimum socially acceptable standard of living - whereas the relative income indicator suggests that poverty is at lower levels in 2014/15 than it was in 2008/09. The same comparison is made in Figure 4 for children and again this demonstrates the different story that is told by these alternative indicators. According to the relative income indicator, the six years following the recession saw an overall reduction in the proportion of children growing up in poverty which could be framed as an increase or improvement in living standards. The below MIS indicator, however, shows an increase in the proportion of children growing up in households that do not have the income needed in order to have a publically defined and agreed minimum living standard - which can reasonably be framed as a decline in living standards.

Take in Figure (No.4) here

The Minimum Income Standard as a 'measure' clearly adds to our understanding of what has happened to living standards since 2008, evidencing the widely held view that the last decade in the UK has been one of the most challenging times for living standards since the early-mid twentieth century. MIS allows us to track the adequacy of incomes, over time, rooted in and based on public consensus about what is needed for a minimum socially 
What the Minimum Income Standard tells us about living standards in the UK

acceptable standard of living. In a period when incomes have been either falling or stagnant, arbitrary indicators of low income and/or poverty pegged to median incomes fail to capture the downward trends in living standards. The MIS benchmark, however, based on the cost of a minimum basket, agreed by the public, offers a different perspective on what has happened to living standards, showing who is at greatest risk of having inadequate income and how this has changed over time. Beyond simply providing an alternative means of tracking living standards, the value of the MIS 'measure' ultimately rests in the definitional task at the heart of the MIS approach. The MIS benchmark is not an arbitrary threshold, devoid of meaning beyond a relationship to the average. It is a 'meaning-full' description, publically determined, of what society agrees everyone should be able to have in order to have a minimum socially acceptable standard of living; a living standard below which individuals and families risk having too few resources to meet their agreed needs.

\section{Conclusion}

This chapter set out to explore what the Minimum Income Standard tells us about contemporary living standards in the UK over the period since the great recession in 2008. The past nine years have seen great economic instability and significant changes in, for example, the ways in which the relationship between the state and the individual is conceived, and the nature and value of state support for those hit hardest by stagnant wages, the rising cost of essentials or, more often than not, both. It is likely that many households will continue to face substantial challenges to their actual living standards over the coming few years; the Office for Budget Responsibility in the UK (2016) suggests that growth in GDP is likely to slow over the next year and beyond, while, for many, pay is unlikely to reach pre-recession levels until at least 2020 (Corlett, Finch, \& Whittaker, 2016).

In the face of these challenging times, the ways in which minimum living standards are defined and described by members of the public have remained remarkably consistent. Changes within the detailed lists of goods and services put together by groups, which together define a minimum living standard, have had more to do with changes in technology, and the ways in which developments in this area enable novel forms of social participation and engagement, rather than being driven by reduced expectations about what a minimum is and how agreed minimum needs should be reasonably met. In other words, austere times have not in general meant an increasingly austere definition of minimum living standards. At the same time, it is clear that a growing number of individuals lack the income necessary to 
meet this publically defined minimum standard of living, and that the well-established means of tracking changes in living standards - relative income measures - do not adequately capture what life has been like for many since 2008. Austere times may not have resulted in a more parsimonious living standard, but they certainly have resulted, for example, in more children growing up in households that do not have the income they need to meet this minimum living standard.

The Minimum Income Standard tells us something about living standards that continues to be of significant value, both in terms of providing a regularly updated, consensually-defined living standard rooted in public understanding of what a minimum is, and in establishing a threshold of income adequacy against which the trajectory of living standards can be tracked. 
What the Minimum Income Standard tells us about living standards in the UK

\section{References}

Belfield, C., Cribb, J., Hood, A., \& Joyce, R. (2014). Living Standards, Poverty and Inequality in the UK: 2014. London, England: The Institute for Fiscal Studies.

Berthoud, R., \& Bryan, M. (2010). Income, deprivation and poverty: a longitudinal analysis. Journal of Social Policy, 40 (1), 135-156.

Brewer, M., Browne, J., \& Joyce, R. (2011). Child and working-age poverty from 2010 to 2020. London, England: The Institute for Fiscal Studies.

Campaign for Better Transport. (2015). Buses in Crisis: A report on bus funding across England and Wales 2010-2016. Retrieved from http://www.bettertransport.org.uk/sites/default/files/research-files/buses-in-crisis-2015.pdf

Chowdry, H., Greaves, E., \& Sibieta, L. (2010). The pupil premium: assessing the options. London, England: Institute for Fiscal Studies.

The Conservative Party. (2010). The Conservative Manifesto 2010: Invitation to join the government of Britain. London, England: The Conservative Party.

Corlett, A., Finch, D., \& Whittaker, M. (2016). Living standards 2016: the experiences of low to middle income households in downturn and recovery. London, England: Resolution Foundation

Cribb, J., Hood, A., Joyce, R., \& Phillips, D. (2013). Living Standards, Poverty and Inequality in the UK: 2013. London, England: The Institute for Fiscal Studies.

Davis, A., Hirsch, D., Padley, M., \& Marshall, L. (2015) How much is enough? Reaching social consensus on minimum household needs. Loughborough, England: Centre for Research in Social Policy.

Davis, A., Hirsch, D., \& Padley, M. (2014). A Minimum Income Standard for the UK in 2014. York, England: Joseph Rowntree Foundation.

Department for Education. (2017). Survey of Childcare and Early Years Providers, England, 2016. London, England: Department for Education.

Department for Work and Pensions, National Centre for Social Research, Office for National Statistics. Social and Vital Statistics Division. (2016). Family Resources Survey, 2014-2015. [data collection]. UK Data Service. SN: 8013, http://doi.org/10.5255/UKDA-SN-8013-1

Department for Work and Pensions. (2017). Households Below Average Income: An analysis of the UK income distribution: 1994/95-2015/16. Retrieved from https://www.gov.uk/government/uploads/system/uploads/attachment_data/file/600091/house holds-below-average-income-1994-1995-2015-2016.pdf

Fitzpatrick, S., Bramley, G., Sosenko, F., Blenkinsopp, J., Johnsen, S., Littlewood, M., \& Watts, B. (2016). Destitution in the UK. York, England: Joseph Rowntree Foundation. 
Foley, P. (2004). Does the Internet help to overcome social exclusion. Electronic Journal of e-government, 2(2), 139-146.

Gordon, D., Mack, J., Lansley, S., Main, G., Nandy, S., Patsios, D., \& Pomati, M. (2013). The impoverishment of the UK PSE UK first results. Bristol, England: PSE-UK.

Haddad, M. (2012). The Perfect Storm: Economic stagnation, the rising cost of living, public spending cuts, and the impact on UK poverty. Oxford, England: Oxfam.

Hargittai, E., \& Hinnant, A. (2008). Digital inequality differences in young adults' use of the Internet. Communication Research, 35(5), 602-621.

Hassani, S. N. (2006). Locating digital divides at home, work, and everywhere else. Poetics, 34(4), 250-272.

Hill, K., Hirsch, D., \& Padley, M. (2015). Minimum budgets for single people sharing accommodation. CRSP Working Paper 642. Loughborough, England: Centre for Research in Social Policy.

Hill, K., Davis, A., Hirsch, D., \& Marshall, L. (2016). Falling Short: the experiences of families living below the Minimum Income Standard. York, England: Joseph Rowntree Foundation.

Hirsch, D. (2013a). A minimum income standard for the UK in 2013. York, England: Joseph Rowntree Foundation.

Hirsch, D. (2013b). Addressing the poverty premium: approaches to regulation. London, England: Consumer Futures.

Hirsch, D. (2015). Will the 2015 summer budget improve living standards in 2020? York, England: Joseph Rowntree Foundation.

Hirsch, D., Padley, M., \& Valadez, L. (2016). A poverty indicator based on a Minimum Income Standard. CRSP Working Paper 656. Loughborough, England: Centre for Research in Social Policy.

HM Government. (2010). The Child Poverty Act 2010. London, England: Her Majesty’s Stationery Office.

HM Government. (2014). The Child Poverty Strategy 2014-17. London, England: Her Majesty’s Stationery Office.

HM Government. (2015). Sporting Future: A New Strategy for an Active Nation. London, England: Her Majesty’s Stationery Office.

Hood, A., \& Waters, T. (2017). Living Standards, Poverty and Inequality in the UK: 2016-17 to 2021-22. London, England: The Institute for Fiscal Studies.

Kyprianou, P. (2015). Getting by? A year in the life of 30 working families in Liverpool. Birmingham, England: Getting By? 
What the Minimum Income Standard tells us about living standards in the UK

The Labour Party. (2010). The Labour Party Manifesto 2010: A future fair for all. London, England: The Labour Party.

The Labour Party. (2015). The Labour Party Manifesto 2015. London, England: The Labour Party.

Livingstone, S., \& Helsper, E. (2007). Gradations in digital inclusion: children, young people and the digital divide. New media \& society, 9(4), 671-696.

Mack, J., \& Lansley, S. (1985). Poor Britain. London, England: George Allen and Unwin.

Office for Budget Responsibility. (2016). Economic and Fiscal Outlook - November 2016. London, England: Office for Budget Responsibility. Retrieved from http://budgetresponsibility.org.uk/download/economic-and-fiscal-outlook-november-2016/

OFCOM. (2016). Adults' media use and attitudes: Report 2016. Retrieved from https://www.ofcom.org.uk/_data/assets/pdf_file/0026/80828/2016-adults-media-use-andattitudes.pdf

Office for National Statistics. (2016). Family spending in the UK: financial year ending March 2016. 2 Retrieved from https://www.ons.gov.uk/peoplepopulationandcommunity/personalandhouseholdfinances/expe nditure/bulletins/familyspendingintheuk/financialyearendingmarch2016\#how-has-the-digitalera-affected-uk-households-spending-habits

Padley, M., \& Hirsch, D. (2013). Households below a Minimum Income Standard: 2008/09 to 2010/11. York, England: Joseph Rowntree Foundation.

Padley, M., \& Hirsch, D. (2014). Households below a Minimum Income Standard: 2008/09 to 2011/12. York, England: Joseph Rowntree Foundation.

Padley, M., \& Hirsch, D. (2016) Households below a Minimum Income Standard: 2008/09 to 2013/14. York, England: Joseph Rowntree Foundation.

Padley, M., Valadez, L., \& Hirsch, D. (2015). Households below a Minimum Income Standard: 2008/09 to 2012/13. York, England: Joseph Rowntree Foundation.

Padley, M., Hirsch, D., \& Valadez, L. (2017). Households below a Minimum Income Standard: 2008/09 to 2014/15. York, England: Joseph Rowntree Foundation.

Plunkett, J., Hurrell, A., \& Whittaker, M. (2014). The State of Living Standards: The Resolution Foundation's annual audit of living standards in Britain. London, England: Resolution Foundation.

Pople, L. (2017). Money and material things. In The Children's Society (Ed.), Understanding Childhoods: Growing up in Hard Times (pp. 34-40). London: The Children's Society.

Rabindrakumar, S. (2013). Paying the price: single parents in the age of austerity. London, England: Gingerbread. 
Ridge, T. (2002). Child Poverty and Social Exclusion. Bristol, England: Policy Press.

Smith, T., Noble, M., Noble, S., Wright, G., McLennan, D., \& Plunkett, E. (2015). The English Indices of Deprivation 2015: Research Report. London, England: Department for Communities and Local Government. Retrieved from

https://www.gov.uk/government/uploads/system/uploads/attachment_data/file/464597/Englis h_Indices_of_Deprivation_2015_-_Research_Report.pdf

Townsend, P. (1979). Poverty in the United Kingdom. Harmondsworth, England: Penguin.

Walker, R. (1987). Consensual Approaches to the Definition of Poverty: Towards and Alternative Methodology. Journal of Social Policy, 16 (2), 213-226.

Whelan, C., Layte, R., Maitre, B., \& Nolan, B. (2001). Income, deprivation and economic strain: an analysis of the European Community Household Panel. European Sociological Review, 17 (4), 357-372. 
Figure 1 Median equivalised income, CPI-adjusted, 2008/09 to 2015/16 $(2008 / 09=100)$

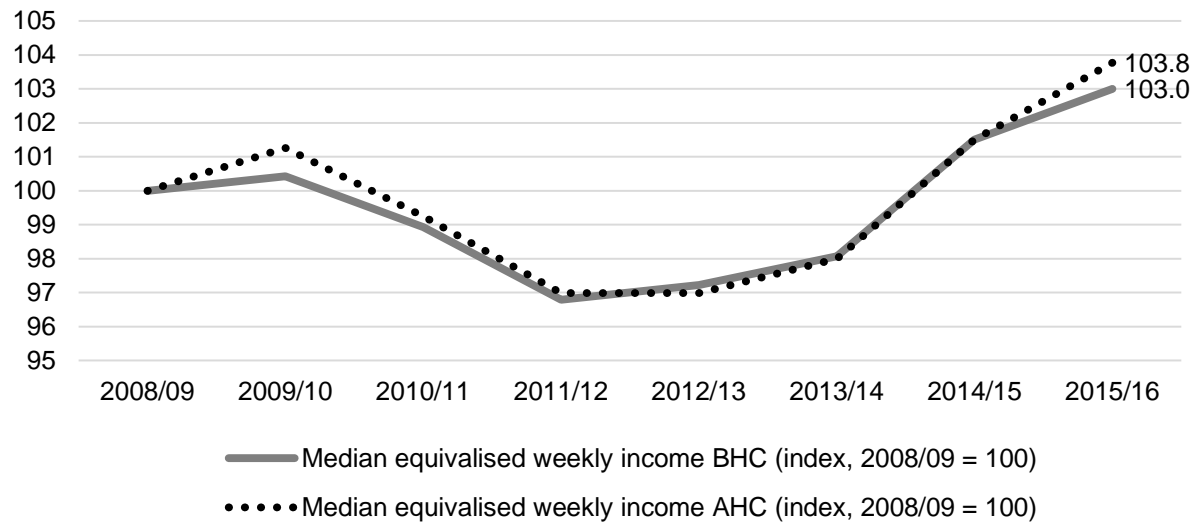

Source: Department for Work and Pensions (2017)

\section{Figure 2 Proportion of individuals below MIS, by demographic groups}

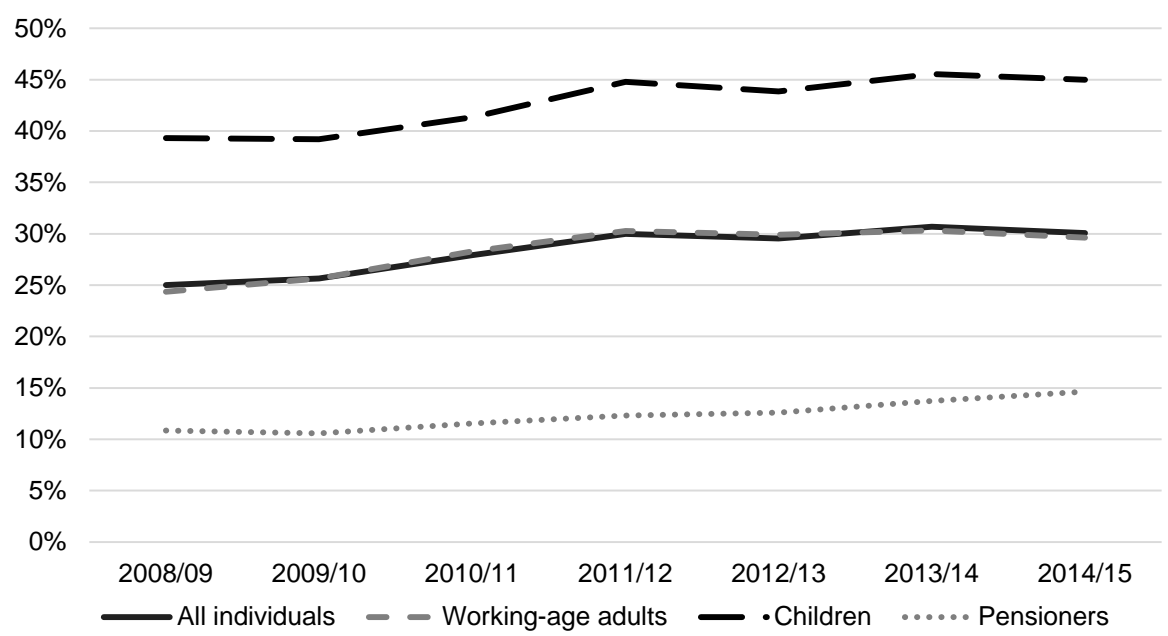


What the Minimum Income Standard tells us about living standards in the UK

Figure 3 Comparison of MIS and relative income indicator, all individuals $(2008 / 09=100)$

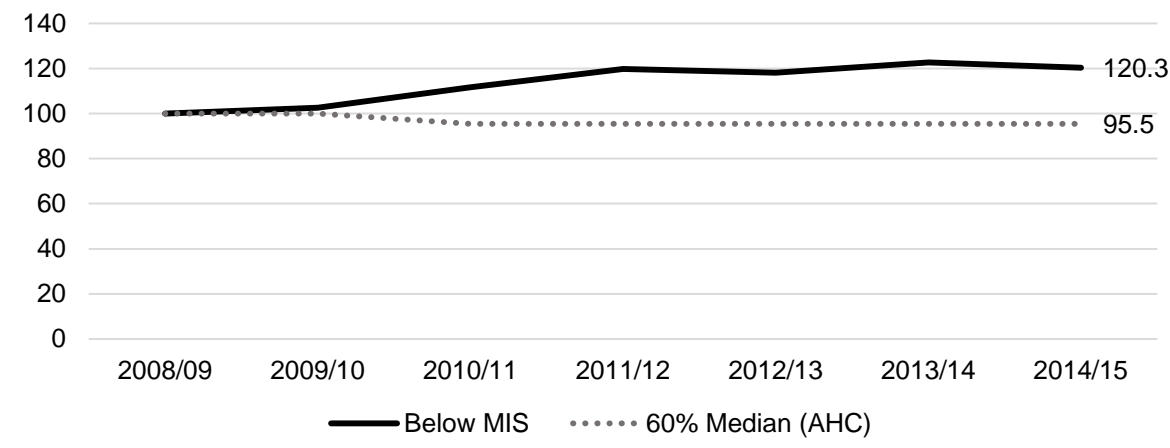

Figure 4 Comparison of MIS and relative income indicator, children $(2008 / 09=$ 100)

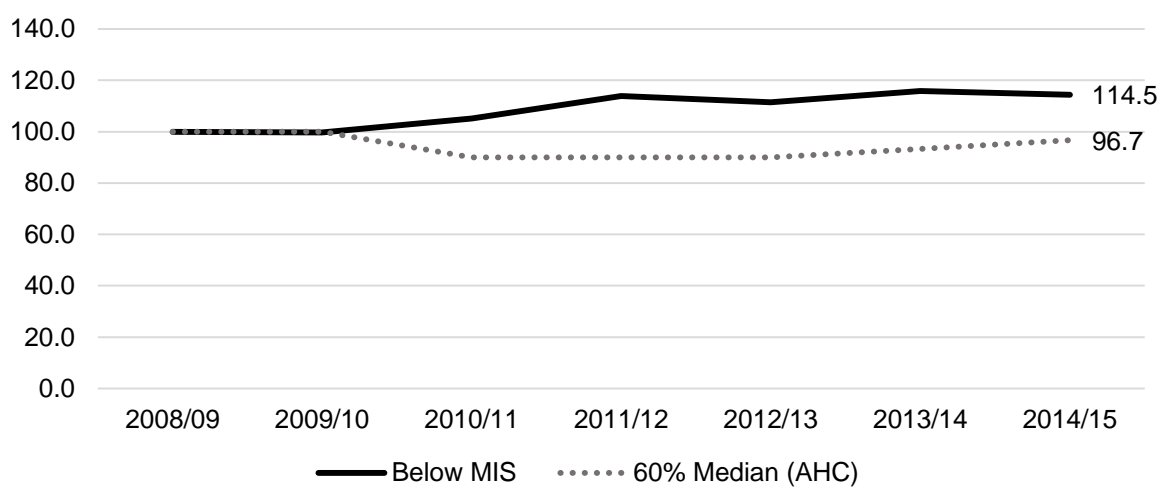

